\title{
Ser objeto de opressão não é ser vítima: uma entrevista com Catarina Martins
}

Being the Target of Oppression is not Being a Victim: an interview with Catarina Martins

\author{
Gabrielle Vivian Bittelbrun' (iD 0000-0003-0888-4288 \\ 'Universidade Federal de Santa Catarina, Florianópolis, SC, Brasil. 88040-900
}

\section{$-$}

Uma multidão de mais de 8 mil pessoas se reuniu para o $13^{\circ}$ Mundos de Mulheres e para o $11^{\circ}$ Fazendo Gênero de 2017. Entre as participantes, estavam pensadoras como a portuguesa Catarina Martins. Professora do Departamento de Línguas, Literaturas e Culturas da Faculdade de Letras e investigadora do Centro de Estudos Sociais da Universidade de Coimbra, Portugal, Catarina tem reconhecida trajetória de publicações de Literatura Comparada e de Literatura de Expressão Alemã e, especialmente, de publicações sobre temas africanos na Literatura Portuguesa e Literaturas Africanas lusófonas, anglófonas e francófonas, em particular de mulheres. Em uma conversa durante o evento, Catarina, que participou de Mesa-redonda e de Simpósio Temático do FG, contou como há muito o que aprender com as mulheres dos países em desenvolvimento e destacou as possibilidades de transformação e resistência em contextos de opressão e em momentos de retrocesso. A autora falou ainda da importância da nova geração de escritoras africanas e da necessidade de o movimento feminista ser autocrítico, para ampliar a inclusão de novos saberes.

Entrevistadora: No trabalho Nós e as mulheres dos outros, a professora demonstra a intenção de refletir sobre a teoria feminista de mulheres africanas e fala do desconhecimento que parece existir no meio acadêmico português sobre esses feminismos africanos. Em parte isso se deve à própria dificuldade de acesso a algumas publicações, como foi até pontuado no trabalho. Mas, de um modo geral, como a professora avalia a receptividade das teorias feministas do Sul no contexto português e, mais amplamente, no contexto europeu?

Catarina Martins: Temos que pensar na diferença de contextos. Os estudos feministas e os estudos de gênero dentro de todas as academias estão num processo de crescimento, mas tiveram um longo período de legitimação. E, no contexto português, mais ou menos periférico na Europa, os estudos feministas, os feminismos europeus e brancos, de várias correntes, têm ainda um programa de afirmação dentro da academia. Imagine então se falarmos em feminismos africanos e não ocidentais. É ainda mais difícil porque todo o viés descolonial ou pós-colonial desses feminismos terá uma dimensão muito grande de crítica aos feminismos europeus. Ou seja, o próprio feminismo que ainda está em um processo de legitimação no contexto europeu, sobretudo aquele que tem intenção fortemente política - que acho que é o único que interessa, este que pretende ser um feminismo transformador -, vai ter que olhar para si próprio e questionar se é um pensamento emancipador ou se só é emancipador dentro do contexto europeu. Estamos a trabalhar pela emancipação das mulheres brancas, europeias, pelos direitos de cidadania, por questões do direito ao corpo e à sexualidade, aos papéis de gênero e das representações, isso é a nossa agenda. Mas vamos ter que ver também como, apesar de termos uma agenda emancipadora, podemos estar a ser opressoras em relação a outras mulheres. É isso que o feminismo europeu, incluindo o português, tem dificuldade em aceitar. Acreditamos na universalidade dos nossos conceitos, ou seja, que se pudemos desconstruir gênero na Europa também podemos desconstruir gênero em África ou na América Latina ou na Ásia. Pensamos que nosso conceito de emancipação, 
com a saída da mulher para trabalhar no âmbito público, é o caminho que todas as mulheres em todos os contextos devem seguir. Portanto, todo esse conjunto de questões adquiridas em toda a Europa teria que ser questionado. O feminismo, ao mesmo tempo em que está a questionar o patriarcado e o domínio dos homens na academia, e em todos os níveis da sociedade, teria que fazer a sua autocrítica ao mesmo tempo; isso é muito difícil. Combinar uma afirmação que ainda é muito necessária com uma autocrítica. E há também, acho eu, toda uma arrogância que ainda é mesmo colonial, na Europa, dificultando esse processo todo.

Entrevistadora: Então, na sua visão, mesmo agora, avançando para a segunda década do século 21 , há resquícios de uma visão eurocentrada no âmbito feminista?

CM: Existe porque achamos que esses conceitos são universais e vão funcionar da mesma maneira, independentemente dos contextos culturais. E há uma ideia dos feminismos do que se chamou de "Terceiro Mundo", ou seja, dos feminismos dos países em desenvolvimento. Há uma ideia de superioridade civilizacional da Europa que faz com que seja uma missão, que as feministas também assumem com orgulho, de "nós vamos salvar as mulheres dos outros", um discurso inclusive partilhado com os discursos políticos conservadores. A própria ideia de construção da Europa foi fundada sobre uma superioridade em relação ao que seria seu reverso, como o "mundo islâmico". Toda a crise dos "refugiados" vai reforçar isso. Os discursos conservadores seguem em grande parte dizendo "eles", os muçulmanos, são mais bárbaros porque tratam pior as mulheres e é um discurso absolutamente hipócrita, porque os setores da direita conservadora não se preocupam minimamente com a emancipação das mulheres, a não ser quando isto serve para derrotar os homens do lado de lá da barricada. E os feminismos acabam por partilhar esse direcionamento, então também adquirem essa missão de "vamos salvá-las" porque "as muçulmanas", ou "as africanas" ou "as outras" são "mais oprimidas do que nós". O que é muito perverso também para as europeias, porque quando estamos a ver que as outras que estão oprimidas, nós não estamos a ver como ainda temos violência doméstica, violência sexual. É uma questão complexa, ainda há muito trabalho a fazer nessa esfera.

Entrevistadora: A professora abrange seus estudos da Alemanha à África. Como é esse processo? CM: Sou doutorada em Literatura Alemã, mas num momento da minha vida fiquei cansada da Europa, da academia e fui para o Senegal, onde dei aulas. Foi onde, com essas mulheres, que aprendi a ser política. São encontros que nos mudam. Mas ainda me dedico à Literatura Alemã também. Para podermos também fazer a crítica do pensamento europeu, temos que conhecê-lo muito bem e o pensamento europeu é em grande parte definido pelo centro da Europa (França, Alemanha, Inglaterra), pelo eixo de pensadores que determinam a modernidade europeia que é exportada para determinar o conhecimento do mundo.

Entrevistadora: Mas, como uma feminista do Norte, quando a professora reconheceu essas linhas abissais de pensamento, quando se deu conta dessas ficções que permeiam a "mulher africana", a "mulher latino-americana", a "mulher asiática"?

CM: Percebi com o contato com outras mulheres, mulheres de outro mundo. Às vezes há momentos de revelação quase pessoal, que não têm a ver com o pensamento acadêmico. Recordo-me da primeira vez em que fui trabalhar no continente africano, no Senegal, onde fui professora durante três anos, quando tinha 27 anos. Eu ia com aquele espírito "eu vou lá ajudar essas pessoas que precisam" e no primeiro contato que tenho vejo mulheres grandes, fortes, poderosas e foram nesses choques que percebi o que estava a fazer. Percebi que não fui ensinar nada a ninguém, só aprender. Venho de um ambiente de classe média em que muitos direitos já estão garantidos. Não é que não venhamos algum dia ser objeto de algum tratamento machista, não estamos imunes a isso. Mas temos uma vida razoavelmente fácil em relação a mulheres que vivem em condição de desenvolvimento muito pior, de falta de acesso à educação, pelos próprios meios em que vivem, pela opressão dentro da família, pela violência. Só que o que eu aprendi é que essas mulheres são objetos de opressão - não vítimas. O que aprendi com elas é que suas estratégias de resistência são muito criativas, muito articuladas e que conseguem sobreviver e encontrar espaços de poder, embora nosso olhar só as veja como vítimas. Vítima aponta para alguém que é impotente, que não resiste. Não quero, por outro lado, glorificar um lugar de opressão, de pobreza, sofrido. O que quero dizer é que elas têm muito a ensinar. Porque nós viemos de um lugar muito mais confortável, onde nunca aprendemos o que elas aprenderam ao longo da vida e de gerações para fazer face a essas opressões. Portanto, o que eu acho que os feminismos do Norte têm que fazer é procurar aprender os saberes dessas mulheres, a forma como se articulam, como resistem, e não estou a falar somente de movimentos organizados, mas do cotidiano, das relações interpessoais para fazer face às opressões. Elas precisam de ajuda e de toda a nossa solidariedade, mas não com um olhar arrogante. Muitas delas podem ser de alguma maneira potenciadas com o que temos a trazer, mas sempre é preciso levar em conta a voz delas em primeiro lugar. Não temos que ir como 
eu ia, pensando "agora eu vou Ihes ensinar", porque eu não sei o que é colher uma manga ou duas e montar uma banca e ficar à espera de vender para conseguir dar de comer aos meus filhos. Não sei o que é levar um filho na mão, outro nas costas e um balde na cabeça. Eu sei que essa mulher precisa de mim, mas eu tenho que saber como ela precisa nos termos dela, porque senão até me arrisco a prejudicá-la. Muitos programas de ajuda ao desenvolvimento tiveram bons resultados, outros foram contestados por causa de prejuízos que trouxeram a estas práticas já consolidadas, a essas estratégias que elas têm de resistência específica nos contextos culturais onde as opressões aconteciam.

Entrevistadora: Na sua visão, o que pode ajudar para um processo de maior igualdade no movimento feminista?

CM: A humildade é uma virtude que temos que ter todos e todas e o feminismo também. $O$ feminismo nos dá alguma força, mas nos dá às vezes alguma arrogância. Quando estamos sozinhas, estamos fracas; quando estamos juntas, estamos fortes e isso é extraordinário, nos fortalece para nossas causas. Mas, ao mesmo tempo, temos um olhar um pouco arrogante em relação às pessoas que estão fora, em relação a outras mulheres que achamos que não estão conscientizadas. Ou pensamos que nossa luta é que vale, sem considerar que outras pessoas escolhem rumos que podem não ser iguais aos nossos, mas podem ter pontos de encontro. Acho que o feminismo às vezes tem essa dimensão. É natural que, como saímos de um lugar de opressão, queremos essa força coletiva. Mas essa força às vezes limita nosso olhar.

Entrevistadora: Em Deixei meu coração em África, a professora mencionou um certo discurso nostálgico se expandindo na mídia e na sociedade sobre os anos em África. Ainda há esse tipo de discurso?

CM: O luso-tropicalismo, termo de Gilberto Freyre, foi muito útil na época salazarista para manutenção do império africano, porque o Brasil já estava independente. "Deixei meu coração em África" é uma citação ao Caderno de Memórias Coloniais, de Isabela Figueiredo, mas que é uma frase que se repete muito dos discursos saudosistas do colonialismo português em África, sobretudo em uma camada da população que chamamos "retornados". Essa designação foi dada aos antigos colonos no momento em que se dá a revolução de 25 de abril e que, portanto, são chamados a retornar à metrópole. Havia muitas dessas pessoas que já tinham nascido em África, mas são obrigadas a regressar porque os países africanos fazem as suas independências e expulsam os colonos. Grande parte regressa em condições muito más, deixando tudo para trás. Na realidade, muitos portugueses foram para a África como emigrantes, ou seja, porque vinham de condição de pobreza em Portugal e em África conseguiram enriquecer mais rapidamente. E quando voltam, ficam em situação de quase marginalidade, porque não são bem aceitos pelos portugueses, que acham que abandonaram a pátria. Na África, deixaram as vidas construídas, bens materiais, trabalho, família etc. E suas memórias ficaram caladas há três décadas e começam a vir à superfície, começam a surgir narrativas, depois de um período de luto. E há duas tendências, que é o que analiso no artigo. Uma é a tendência crítica, como a posição de Isabel Figueiredo que desmonta os mitos sobre esses processos, e há ainda outra tendência muito forte que começa a ser posta em causa. É a nostalgia do Império, mas uma nostalgia racista e colonialista, ou seja, "a África ainda é nossa". Isso apaga o que o colonialismo fez de mal e recupera justamente a retórica luso-tropicalista; os portugueses fizeram um colonialismo "bonzinho", até nos misturarmos. Luso-tropicalismo quer dizer licença para violar, mas aparece como um elogio à mestiçagem. A discussão sobre o racismo está a surgir em Portugal. Há poucas semanas surgiu o primeiro debate televisivo sobre se o país é racista, nem o debate sobre isso era feito. Partia-se do princípio de que Portugal não era um país racista. O tema surgiu a partir de um caso policial de violência e agora ao menos se tem debatido sobre isso.

Entrevistadora: Recentemente, algumas autoras africanas têm alcançado o mainstream. É o caso, especialmente, de Chimamanda Ngozi Adichie. O que a professora acha que foi fundamental para que uma autora como ela atingisse o grande público (já que muitas escritoras africanas excelentes permanecem desconhecidas da grande massa)?

CM: Há vários fatores. Chimamanda é muito boa, mesmo antes dessa projeção. Ela tem qualidade literária e há características da personalidade dela, que é uma excelente comunicadora, que contribuem para que se torne mediatizável. É um produto africano que o Ocidente não tem dificuldade em assumir. Ela consegue uma proeza admirável, ela consegue manter-se fiel à sua origem africana, mas consegue comunicar de uma maneira que o africano se torna aceitável, ou seja, cobre um pouco o fosso da estranheza. Porque há outras teóricas que se mantêm mais numa posição de alteridade irredutível e aí essa comunicação não funciona, muitas vezes não por culpa delas, mas pelas dinâmicas do Ocidente. E há uma questão de mercado, é uma questão de geração, Chimamanda nasceu na década de 1970. Temos autoras que escreveram antes e 
que não conseguiram chegar ao mercado Ocidental porque não era globalizado. E acho que a Chimamanda tem a capacidade de colocar os problemas profundos de ordem teórica em uma linguagem muito simples e ela tem sido um instrumento fundamental. O que acho, por vezes, é que o risco que ela corre, e que tem que ser corrido, é de ser tomada como a "africana modelo", como se disséssemos "essa africana aceitamos, ela fala nossa a linguagem, enquanto as outras seriam atrasadas, primitivas". Como se ela fosse a mulher negra que nós tomamos para dizer que somos muito bonzinhos e demos lugar aos africanos. A Chimamanda sabe resistir a isso, são dinâmicas alheias a ela. Ela não se deixa apanhar. Mas acho que ela, com toda a sua beleza, torna-se um produto que o Ocidente não tem dificuldade em consumir e que conforta um pouco as consciências imperialistas. Ou seja, se me acusarem de que nunca ouvi uma africana falar, eu já ouvi a Chimamanda. Até porque veio de um meio, de classe média, meio culto. Ela é inteligentíssima e está fazendo um papel muito importante. Mas há muitas outras, que estão escrevendo também e têm a sua projeção. Há uma diáspora africana para o Norte e muitas estão a escrever, criar conceitos e isso deve ser divulgado.

Entrevistadora: Tem havido uma abertura maior para essas autoras?

CM: Há uma abertura maior, não sei se corresponderá a uma transformação política. Acho que não, acho que é só questão de mercado, mas talvez seja um pessimismo meu. Seria a literatura que compensa nossos desejos do exótico. Em Americanah (2014) ela justamente critica isso, a forma como é exotizada.

Entrevistadora: Como o movimento feminista pode contribuir como uma forma de resistência, frente aos retrocessos e ao avanço do conservadorismo no mundo e, mais especificamente, no Brasil?

CM: Essas políticas que estão ocorrendo no Brasil outros países também sofreram, que é o retrocesso para a direita, neoliberais, neoextrativistas, políticas de austeridade, corte nos serviços públicos etc. Aconteceu em Portugal e nas Áfricas. Se toda a sociedade sofre, as mulheres, que estão no fundo da hierarquia do poder, são as que mais sofrem. Por outro lado, aí é que as resistências podem surgir com mais força. As mulheres africanas, por exemplo, têm sido fundamentais no combate às multinacionais que retiram a água e as terras por causa da mineração. Elas têm assumido essa luta contra o capitalismo internacional talvez até mais do que contra o patriarcado, embora seja necessário destacar que nos países africanos cada vez mais essas políticas trazem consigo um reforço da masculinização do Estado e as mulheres acabam muito mais desprotegidas do que estariam dentro de configurações mais tradicionais de sua sociedade. Nos países africanos, um Estado que é corrupto, irresponsável e impune se reproduz nas esferas de governação local e chega às lideranças tradicionais que muitas vezes eram exercidas por mulheres, a exemplo do contexto da África Ocidental, mas deixaram de ser. Essa impunidade do Estado que usurpa 0 poder, que vende os recursos, que expolia um povo vai se reproduzindo no nível social, em tudo e, portanto, vai se repercutindo sobre as mulheres. Portanto, acho que das mulheres deve vir essa força de transformação, por razões de sobrevivência. Onde há um homem que sofre, há sempre uma mulher que sofre o dobro ou o triplo. A luta contra o capitalismo, o patriarcalismo e o colonialismo, como diz o Boaventura de Sousa Santos, "o monstro de três cabeças", tem que vir sempre em conjunto e não são os homens que vão abdicar dos privilégios que têm porque acordaram um dia com boas intenções.

Entrevistadora: A professora é sempre muito engajada também com as causas políticas. Qual o papel que a teoria feminista deve ter, na sua visão, na política?

CM: Na política, a teoria feminista é absolutamente necessária enquanto paradigma crítico transversal do conhecimento que mostra como o poder é realmente marcado por questões patriarcais. Acho que ainda temos que lutar pela questão da representatividade no espaço político, podendo as mulheres que se tornam representantes políticas ser até antifeministas, sabemos disso. Porque tende a haver uma diferença na forma de as mulheres fazerem política, porque há um cuidado maior em relação às desigualdades e uma maior atenção. Não quero essencializar as mulheres, mas elas tiveram que lutar muito mais que os homens, há uma consciência de luta e aprendizagem. Em Portugal, por exemplo, os homens chegam ao poder por meio de redes, quase clubes masculinos. E chegam nos lugares de poder sem um aprendizado político, sem contato com bases militantes, movimentos sociais, enquanto as mulheres, sobretudo as mulheres da esquerda, vêm com esse aprendizado, com um olhar mais aberto. Mulheres jovens em Portugal, bem formadas, mas jovens, têm se destacado por mudar a política europeia. Isso não as livra, no entanto, de discriminações dos homens, mesmo nos movimentos de esquerda. Mas elas se obrigaram a pensar que a política pode ser de outra maneira; criaram um outro lugar para a política, falando com competência, clareza, de um lugar de simplicidade, de sua juventude. 


\section{Referências}

ADICHIE, Chimamanda Ngozi. Americanah. Tradução de Julia Romeu. São Paulo: Companhia das Letras, 2014.

FIGUEIREDO, Isabela. Caderno de memórias coloniais. Coimbra: Angelus Novus, 2009.

MARTINS, Catarina. "Deixei meu coração em África. Memórias Coloniais no feminino". Oficina do Centro de Estudos Sociais, n. 375, p. 1-31, nov. 2011.

MARTINS, Catarina. Nós e as mulheres dos Outros. Feminismos entre o Norte e a África. 27p. Disponibilizado pela autora em https://www.academia.edu/23958651/N\%C3\%B3s_e_as_Mulheres _dos_Outros._Feminismos_entre_o_Norte_e_a_\%C3\%81 frica. Acesso em 05/09/2017.

Gabrielle Vivian Bittelbrun (gabrielle.bittelbrun@gmail.com) é doutora em Literatura pela Universidade Federal de Santa Catarina e integrante do Núcleo Literatual - Estudos Feministas e Pós-Coloniais de Narrativas da Contemporaneidade (UFSC). Professora de Jornalismo da Universidade de Blumenau (Furb), mestra em Jornalismo pela UFSC e jornalista pela Universidade Estadual Paulista Júlio de Mesquita Filho (Unesp).

COMO CITAR ESSE ARTIGO DE ACORDO COM AS NORMAS DA REVISTA

BITTELBRUN, Gabrielle Vivian. "Ser objeto de opressão não é ser vítima: uma entrevista com Catarina Martins". Revista Estudos Feministas, Florianópolis, v. 27, n. 2, e56164, 2019.

\section{CONTRIBUIÇÃO DE AUTORIA}

Não se aplica

\section{FINANCIAMENTO}

Bolsa Capes de Pós-Graduação durante Doutorado em Literatura pela UFSC (2014-2017)

\section{CONSENTIMENTO DE USO DE IMAGEM}

Não se aplica

APROVAÇÃO DE COMITÊ DE ÉTICA EM PESQUISA

Não se aplica

\section{CONFLITO DE INTERESSES}

Não se aplica

\section{LICENÇA DE USO}

Este artigo está licenciado sob a Licença Creative Commons CC-BY Internacional. Com essa licença você pode compartilhar, adaptar, criar para qualquer fim, desde que atribua a autoria da obra.

\section{HISTÓRICO}

Recebida em 02/04/2018

Aprovada em 17/06/2019 